\title{
Serological and molecular identification of Turnip mosaic virus in some wild plants in Iran
}

\author{
H. Valouzi $^{1}$ - A. Golnaraghi ${ }^{2}$ L. Abedini-Aminabad ${ }^{1} \cdot$ M. Diyanat $^{3}$
}

Received: 16 August 2016 / Accepted: 4 December 2016/Published online: 28 December 2016

(C) Australasian Plant Pathology Society Inc. 2016

\begin{abstract}
Forty leaf samples were collected from symptomatic wild plants grown in natural ecosystems in northeast of Tehran. These plant samples were tested by enzyme-linked immunosorbent assay (ELISA) using broad-spectrum potyvirus antibodies. Turnip mosaic virus (TuMV) was identified in four ELISA-positive samples by sequencing of their $3^{\prime}$ end of genomes and subsequently by specific ELISA tests. This study reports Arctium lappa and Sinapis arvensis as new hosts for TuMV in Iran. The results also seem to indicate the possible presence of a new genogroup of the virus.
\end{abstract}

Keywords Arctium lappa $\cdot$ Sinapis arvensis $\cdot$ Turnip mosaic virus $\cdot$ Serological assays $\cdot$ Potyvirus universal primers .

Sequence analysis

Turnip mosaic virus (TuMV), genus Potyvirus (family Potyviridae), infects more than 300 mono- and dicotyledonous plant species in at least 156 genera and 43 families, including cultivated and wild plants, throughout the world (Ohshima et al. 2002; Nayudu 2008). Phylogenetic studies have shown that different virus isolates collected from around the world have

A. Golnaraghi

agolnaraghi@yahoo.com

1 Department of Plant Pathology, College of Agriculture and Natural Resources, Science and Research Branch, Islamic Azad University (IAU), P.O. Box 14515-775, Tehran, Iran

2 Department of Plant Protection, College of Agriculture and Natural Resources, Science and Research Branch, Islamic Azad University (IAU), P.O. Box 14515-775, Tehran, Iran

3 Department of Weed Science, College of Agriculture and Natural Resources, Science and Research Branch, Islamic Azad University (IAU), P.O. Box 14515-775, Tehran, Iran been categorized into five main TuMV genogroups called basal-Brassica (basal-B), basal-Brassica/Raphanus (basalBR), Asian-Brassica/Raphanus (Asian-BR), world-Brassica (world-B) and orchis group; the results have suggested that TuMV might have first spread to Eurasian brassica crops from wild orchids (Nguyen et al. 2013). Widespread occurrence of TuMV in Iran has been previously reported in field crops, vegetables, ornamentals and weeds. Phylogenetic analyses have indicated a clustering of Iranian isolates of the virus into the basal-B and Asian-BR genogroups (Shahraeen et al. 2003; Farzadfar et al. 2005, 2009; Farzadfar and Pourrahim 2014). Detection of TuMV in these reports was done primarily using specific diagnostics tests. Reverse transcription coupled with polymerase chain reaction (RT-PCR) amplifications with universal primers, followed by sequencing and sequence analysis, have facilitated the fast and accurate detection of many virus species in the genus Potyvirus (Zheng et al. 2010).

During the year of 2012, natural ecosystems in northeast of Tehran province of Iran were surveyed and 40 leaf samples were collected from wild plants showing virus-like symptoms. Potyvirus infection of the samples was initially tested by platetrapped enzyme-linked immunosorbent assay (PTA-ELISA) using the broad-spectrum potyvirus antibodies (Bioreba, Switzerland). ELISA results revealed a positive reaction of 33 samples to the potyvirus antibodies. Mosaic, vein clearing, leaf deformation and chlorosis symptoms were associated with virus infections (Fig. 1). Total RNA was extracted from 12 virus-infected samples using a $\mathrm{LiCl}$ protocol (De Fatima et al. 2011). RT-PCR was done using NIb degenerate primers, according to previously published recommendations (Zheng et al. 2010). The RT-PCR tests resulted in the amplification of fragments with the expected size of ca. $0.35-\mathrm{kb}$ for eight samples tested. Nucleotide sequences of the amplicons were determined and analyzed by BLASTN. Isolates which their partial NIb sequences showed the highest identities to TuMV 
were selected for further analysis. The isolates were Th-W505 and Th-W513 [obtained from greater burdock (Arctium lappa, Asteraceae)], Th-W519 (from an unknown brassica) and Th-W525 [from charlock mustard (Sinapis arvensis, Asteraceae)]. All the isolates were collected from mountains in Afjeh village in Lavasanat District (Shemiranat County). To this end, the 3'end genomes of the four isolates were first amplified. As we found WCIEN primer (Pappu et al. 1993) not suitable for direct PCR sequencing, we designed a primer (NWCIEN: 5'- GCATATGGGGTGAGAGAGGT CGTGIATHGANAATGG-3') by adding a 19-nts at 5'end of it and used the new primer in combination with Tu3T9M (Tan et al. 2005) in RT-PCR to amplify this region. The cycling profile was: $94{ }^{\circ} \mathrm{C}$ for $4 \mathrm{~min}, 38$ cycles of $94{ }^{\circ} \mathrm{C}$ for $1 \mathrm{~min}, 50^{\circ} \mathrm{C}$ for $45 \mathrm{~s}, 72{ }^{\circ} \mathrm{C}$ for $1 \mathrm{~min}$, and finally $72{ }^{\circ} \mathrm{C}$ for $10 \mathrm{~min}$. The RT-PCR tests produced DNA fragments with the expected size of ca. $0.7 \mathrm{kbp}$. The primers Pseq (5'GCATATGGGGTGAGAGAGG-3') or Nseq (5'-ATGG GGTGAGAGAGGTCGTG-3') were then used for the sequencing of NWCIEN/Tu3T9M PCR products. Finally, the gap between the $\mathrm{NIb}$ and $\mathrm{CP}$ regions was amplified (amplicons of ca. $1.2 \mathrm{kbp}$ ) using two new primers (TuNIb1P: 5'-TGCGAYGCWGATGGCTCAC-3' and Tu3'seq: 5'-TATGGTCGGTCTTGGTTACG-3'), designed on the basis of the sequences obtained for the isolates, and sequenced. The sequences obtained from the core NIb region to 3'UTR were then assembled to form sequences of $2000 \mathrm{nts}$ and deposited in GenBank (accession nos. KU962950, KU962951, KU962953 and KU962955). BLASTN analysis showed that these sequences matched that of TuMV with the identity scores of $88-89 \%$. Based on BLASTP results, the putative amino acid sequences of the coding regions of these sequences showed 94-95\% identities to the virus. To confirm virus species identification, the four virus isolates were tested by double-antibody sandwich ELISA (DAS-ELISA) using TuMV-specific antibodies (Bioreba). The company provided all the buffers as well as negative and positive controls used. The isolates had positive reactions to the specific antibodies, clearly indicating the presence of TuMV.

The nucleotide sequences of the four Iranian isolates of TuMV and 34 representative non-recombinant sequences of the virus (Nguyen et al. 2013) were evaluated for evidence of recombination by using RDP4 software according to the earlier reports (Farzadfar et al. 2009; Nguyen et al. 2013). Finally, no 'clear' recombination was found in the coding and noncoding regions of the isolates studied. Therefore, all of the 38 sequences were used for phylogenetic analysis. In this study, sequences of one Scallion mosaic virus (ScMV) and one Narcissus yellow stripe virus (NYSV) were used for outgroups (Ohshima et al. 2002). The coding regions of TuMV sequences and the outgroups were aligned and degapped (Ohshima et al. 2002; Farzadfar et al. 2009). Phylogenetic relationships of these sequences were investigated by maximum-likelihood (ML) and neighbour-joining (NJ) algorithms implemented in Mega 6.0 software. For ML analysis, general time-reversible model with a proportion of invariant sites and a gamma distribution of site-rate variants across four categories (GTR $+\mathrm{G}+\mathrm{I}$ ) were used; the trees were found by subtree pruning and regrafting trees (Zheng et al. 2010). Also, the Kimura two-parameter model was used to construct $\mathrm{NJ}$ trees. Both methods were done using 1000 bootstraps to estimate node significances. The NJ tree is shown in Fig. 2. Based on the results, all of the trees partitioned most of the sequences into the five consistent groups, and the orchis group was a sister group to all others in the trees (Nguyen et al. 2013). The four Iranian isolates fell into a separate cluster. Moreover, sequence analysis of the degapped sequences showed that the four TuMV isolates had $95.4-97.4 \%$ identities with each other, and $85.8-86.3 \%$ identities to the other Iranian isolates.

In this study, we used universal primers for the detection of TuMV in wild plants in some natural ecosystems in Tehran. The results revealed the capacity of universal primers, especially NIb primers, to amplify a part of genomes of Iranian potyvirus isolates, similar to an earlier report (YazdaniKhameneh et al. 2013). Our results also showed the efficacy of NWCIEN primers, and Pseq and Nseq for RT-PCR amplifications and direct PCR sequencing of 3'end genomes of potyvirus isolates. We found greater burdock and charlock mustard as susceptible hosts for TuMV in the mid-Eurasian region of Iran. However, it seems that TuMV has many other natural hosts, belonging to different plant families, in the country as previous studies have shown a Eurasian origin for the virus (Tomimura et al. 2003). Although the four isolates
Fig. 1 Symptoms associated with Turnip mosaic virus (TuMV) infections on a greater burdock (Arctium lappa) and $\mathbf{b}$ charlock mustard (Sinapis arvensis)
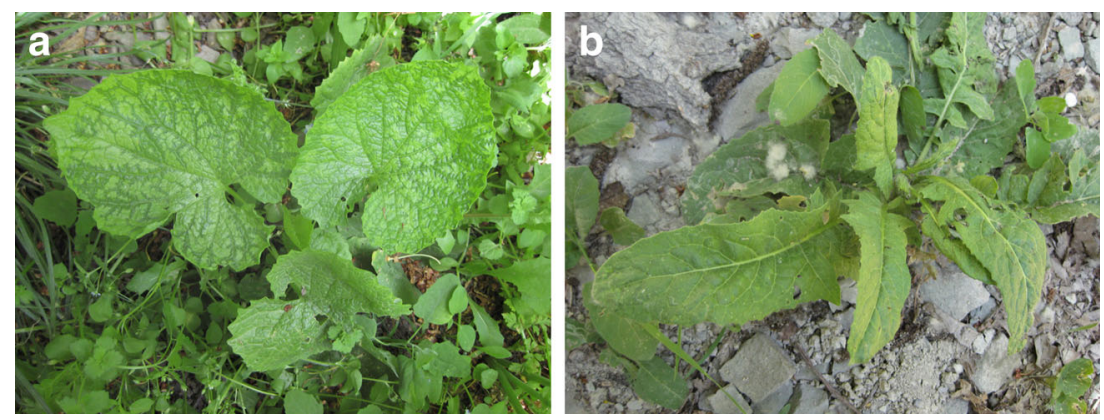
Fig. 2 A neighbor-joining tree indicating the relationships between the nucleotide sequences obtained for the four Iranian isolates of Turnip mosaic virus (TuMV) from wild plants with the other 34 isolates. The tree was constructed from the polyprotein sequences of various nonrecombinant isolates of the virus identified in earlier studies (Nguyen et al. 2013). Numbers at each node indicate the percentage of supporting bootstrap samples in NJ and ML methods, respectively (only values equal to or more than $50 \%$ are shown). Horizontal branch lengths are drawn to scale with the bar indicating $0.05 \mathrm{nt}$ replacements per site. The name of each isolate, original host plant and accession code in the international gene sequence database are listed

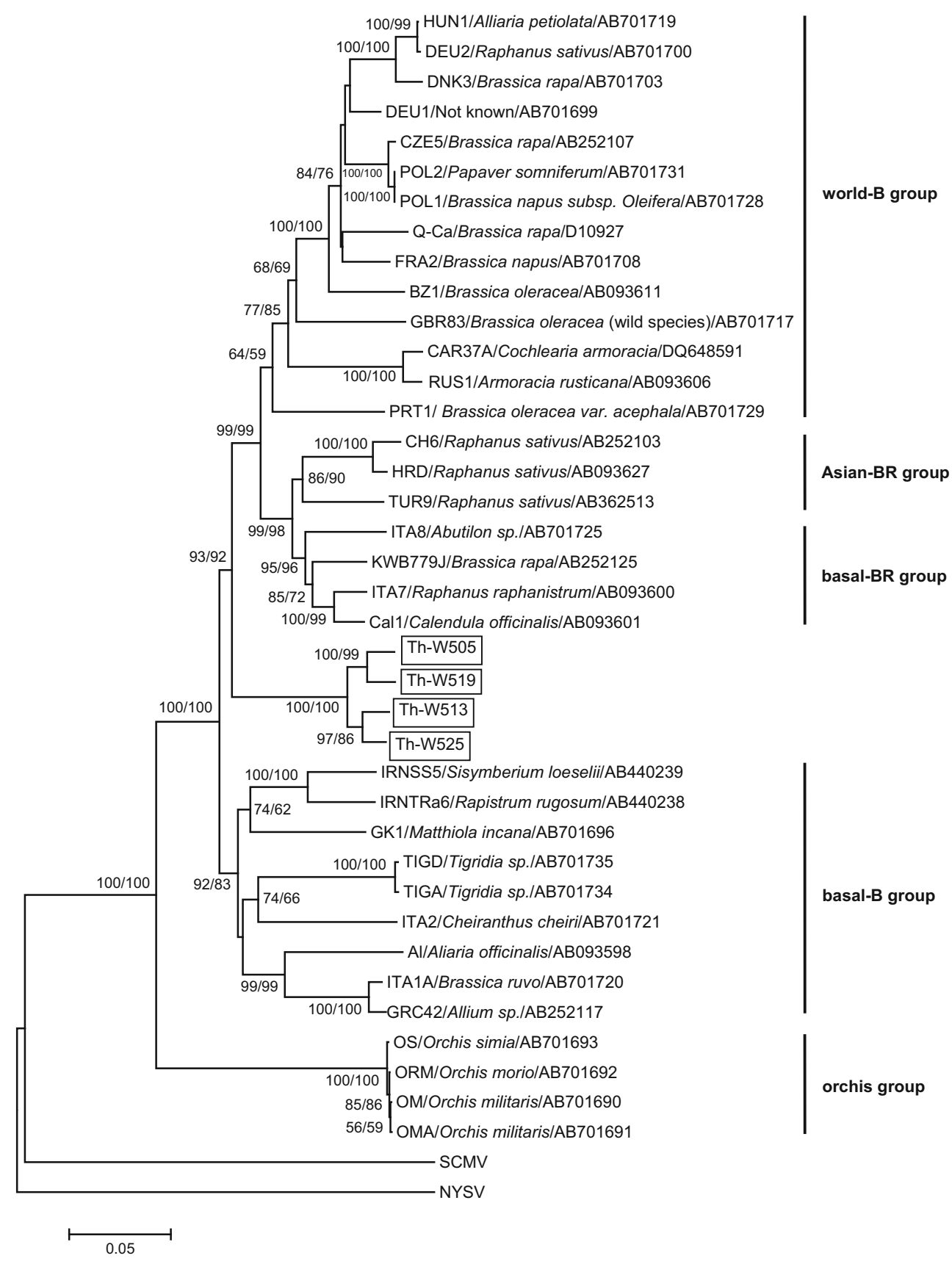

Acknowledgements We wish to thank Prof. K. Ohshima (Laboratory of Plant Virology, Faculty of Agriculture, Saga University, Japan) for his kindly helps in our studies on the detection and identification of potyviruses in wild plants in Iran. This work was supported by grants from the Iranian Group for the Promotion of Science, IGPS, nos. 91001003,92001005 and 94001002 .

\section{References}

De Fatima Rosas-Cardenas F, Duran-Figueroa N, Vielle-Calzada JP, Cruz-Hernandez A, Marsch-Martinez N, de Folter S (2011) A simple and efficient method for isolating small RNAs from different plant species. Plant Methods 7:4 
Farzadfar S, Pourrahim R (2014) Characterization of Turnip mosaic virus from the Asian-BR population in Iran. J Phytopathol 162:824-828

Farzadfar S, Ohshima K, Pourrahim R, Golnaraghi AR, Jalali S, Ahoonmanesh A (2005) Occurrence of Turnip mosaic virus on ornamental crops in Iran. Plant Pathol 54:261

Farzadfar S, Tomitaka Y, Ikematsu M, Golnaraghi AR, Pourrahim R, Ohshima K (2009) Molecular characterization of Turnip mosaic virus isolates from Brassicaceae weeds. Eur J Plant Pathol 124:45-55

Nayudu MV (2008) Plant Viruses. Tata McGraw-Hill Publishing Company Limited, New Delhi, India

Nguyen HD, Tomitaka Y, Ho SYW, Duchene S, Vetten HJ et al (2013) Turnip mosaic Potyvirus probably first spread to Eurasian brassica crops from wild orchids about 1000 years ago. PLoS One 8:e55336

Ohshima K, Yamaguchi Y, Hirota R, Hamamoto T, Tomimura K, Tan Z et al (2002) Molecular evolution of Turnip mosaic virus; evidence of host adaptation, genetic recombination and geographical spread. J Gen Virol 83:1511-1521

Pappu SS, Brand R, Pappu HR, Rybicki EP, Gough KH, Frenkel MJ, Niblett CL (1993) A polymerase chain reaction method adapted for selective amplification and cloning of $3^{\prime}$ sequences of potyviral genomes: application to dasheen mosaic virus. J Virol Methods 41:9-20

Shahraeen N, Farzadfar S, Lesemann DE (2003) Incidence of viruses infecting winter oilseed rape (Brassica napus ssp. oleifera) in Iran. J Phytopathol 151:614-616

Tan Z, Gibbs AJ, Tomitaka Y, Sanchez F, Ponz F, Ohshima K (2005) Mutations in Turnip mosaic virus genomes that have adapted to Raphanus sativus. J Gen Virol 86:501-510

Tomimura K, Gibbs AJ, Jenner CE, Walsh JA, Ohshima K (2003) The phylogeny of Turnip mosaic virus; comparisons of thirty-eight genomic sequences reveal a Eurasian origin and a recent 'emergence' in East Asia. Mol Ecol 12:2099-2111

Wylie SJ, Luo H, Li H, Jones MG (2012) Multiple polyadenylated RNA viruses detected in pooled cultivated and wild plant samples. Arch Virol 157:271-284

Yazdani-Khameneh S, Golnaraghi AR, Rakhshandehroo F (2013) A potyvirus of Malva neglecta in Iran. J Plant Pathol 95:666

Zheng L, Rodoni BC, Gibbs MJ, Gibbs AJ (2010) A novel pair of universal primers for the detection of potyviruses. Plant Pathol 59:211-220 